\title{
Psychological factors are associated with subjective cognitive complaints 2 months post-stroke
}

Citation for published version (APA):

Nijsse, B., van Heugten, C. M., van Mierlo, M. L., Post, M. W. M., de Kort, P. L. M., \& Visser-Meily, J. M. A. (2017). Psychological factors are associated with subjective cognitive complaints 2 months post-stroke. Neuropsychological Rehabilitation, 27(1), 99-115. https://doi.org/10.1080/09602011.2015.1065280

Document status and date:

Published: 01/01/2017

DOI:

10.1080/09602011.2015.1065280

Document Version:

Publisher's PDF, also known as Version of record

Document license:

Taverne

Please check the document version of this publication:

- A submitted manuscript is the version of the article upon submission and before peer-review. There can be important differences between the submitted version and the official published version of record.

People interested in the research are advised to contact the author for the final version of the publication, or visit the DOI to the publisher's website.

- The final author version and the galley proof are versions of the publication after peer review.

- The final published version features the final layout of the paper including the volume, issue and page numbers.

Link to publication

\footnotetext{
General rights rights.

- You may freely distribute the URL identifying the publication in the public portal. please follow below link for the End User Agreement:

www.umlib.nl/taverne-license

Take down policy

If you believe that this document breaches copyright please contact us at:

repository@maastrichtuniversity.nl

providing details and we will investigate your claim.
}

Copyright and moral rights for the publications made accessible in the public portal are retained by the authors and/or other copyright owners and it is a condition of accessing publications that users recognise and abide by the legal requirements associated with these

- Users may download and print one copy of any publication from the public portal for the purpose of private study or research.

- You may not further distribute the material or use it for any profit-making activity or commercial gain

If the publication is distributed under the terms of Article $25 \mathrm{fa}$ of the Dutch Copyright Act, indicated by the "Taverne" license above, 


\title{
Psychological factors are associated with subjective cognitive complaints 2 months post-stroke
}

\author{
Britta Nijsse $^{1}$, Caroline M. van Heugten ${ }^{2,3}$, Marloes L. van \\ Mierlo ${ }^{4}$, Marcel W. M. Post ${ }^{4}$, Paul L. M. de Kort ${ }^{1}$, \\ and Johanna M. A. Visser-Meily ${ }^{4}$
}

${ }^{1}$ Department of Neurology, St Elisabeth Hospital, Tilburg, The Netherlands ${ }^{2}$ Department of Psychiatry and Neuropsychology, School for Mental Health and Neuroscience, Maastricht University, Maastricht, The Netherlands ${ }^{3}$ Department of Neuropsychology \& Psychopharmacology, Faculty of Psychology \& Neuroscience, Maastricht University, Maastricht, The Netherlands ${ }^{4}$ Brain Center Rudolf Magnus and Center of Excellence for Rehabilitation Medicine, University Medical Center Utrecht and De Hoogstraat Rehabilitation, Utrecht, The Netherlands

(Received 23 February 2015; accepted 17 June 2015)

The aim of this study was to investigate which psychological factors are related to post-stroke subjective cognitive complaints, taking into account the influence of demographic and stroke-related characteristics, cognitive deficits and emotional problems. In this cross-sectional study, 350 patients were assessed at 2 months post-stroke, using the Checklist for Cognitive and Emotional consequences following stroke (CLCE-24) to identify cognitive complaints. Psychological factors were: proactive coping, passive coping, self-efficacy, optimism, pessimism, extraversion, and neuroticism. Associations between CLCE-24 cognition score and psychological factors, emotional problems (depressive symptoms and anxiety), cognitive deficits, and demographic and stroke characteristics were examined using Spearman correlations and multiple regression analyses. Results showed that 2 months post-stroke, 270 patients

Correspondence should be addresed to Anne J. M. A. Visser-Meily, Brain Center Rudolf Magnus and Center of Excellence for Rehabilitation Medicine, University Medical Center Utrecht, P.O. Box 85500, 3508 GA Utrecht, The Netherlands. E-mail: j.m.a.visser-meily@umcutrecht.nl

No potential conflict of interest was reported by the authors.

This research project is funded by the VSB foundation and co-ordinated by ZonMw (Dutch Organization for Health Research and Development).

(C) 2015 Informa UK Limited, trading as Taylor \& Francis Group 
(68.4\%) reported at least one cognitive complaint. Age, sex, presence of recurrent stroke(s), comorbidity, cognitive deficits, depressive symptoms, anxiety, and all psychological factors were significantly associated with the CLCE-24 cognition score in bivariate analyses. Multiple regression analysis showed that psychological factors explained $34.7 \%$ of the variance of cognitive complaints independently, and $8.5 \%(p<.001)$ after taking all other factors into account. Of all psychological factors, proactive coping was independently associated with cognitive complaints $(p<.001)$, showing that more proactive coping related to less cognitive complaints. Because cognitive complaints are common after stroke and are associated with psychological factors, it is important to focus on these factors in rehabilitation programmes.

Keywords: Stroke; Rehabilitation; Cognitive complaints; Psychological factors.

\section{INTRODUCTION}

Cognitive impairment is common in up to $50 \%$ of stroke patients, in both the subacute and chronic phase (Duits, Munnecom, van Heugten, \& van Oostenbrugge, 2008). It is a significant factor in long-term disability, contributing to reduced functional outcome for at least five years post-stroke (BarkerCollo, Feigin, Parag, Lawes, \& Senior, 2010). To date, most studies investigating post-stroke cognition have focused on objective assessment using neuropsychological tests, whereas from patients' perspectives their experience of cognitive dysfunction in everyday life matters most (Pollock, St George, Fenton, \& Firkins, 2014). Furthermore, cognitive complaints have been shown to influence quality of life in healthy elderly (van Rijsbergen, Mark, de Kort, \& Sitskoorn, 2014) and subarachnoid haemorrhage patients (Passier et al., 2012; Visser-Meily, Rhebergen, Rinkel, van Zandvoort, \& Post, 2009). A systematic review, published recently by van Rijsbergen et al. (2014), shows a prevalence of subjective cognitive complaints, assessed between 1 month and 54 months after stroke, varying between $28.6 \%$ and $90.2 \%$. According to this review, there are inconsistent results about the association between objective cognitive impairment and subjective cognitive complaints. Some studies found that patients with subjective cognitive complaints also had poorer objective cognitive performance, whereas other studies did not observe such a relationship (van Rijsbergen et al., 2014). Hence, the presence and nature of this relationship is still a matter of debate and there is a need for more insight into the factors associated with cognitive complaints in stroke patients.

Neither demographic characteristics nor stroke-related factors seem to be related to cognitive complaints after stroke, whereas the relationship between cognitive complaints and depressive symptoms is reported frequently 
(van Rijsbergen et al., 2014). However, only two studies performed multivariate analyses (Lamb, Anderson, Saling, \& Dewey, 2013; Xiong et al., 2011), showing that more depressive symptoms were independently significantly associated with (more) cognitive complaints. Nevertheless, much variance is still unexplained.

A theoretical model, proposed by Niederehe (1998), considers personality factors and/or other general cognitive traits and beliefs are potential contributors to subjective cognitive complaints. From a cognitive psychology perspective, memory self-reports are based in the domain of cognitive skills known as metamemory (Niederehe, 1998). Metamemory involves knowledge about memory in general, monitoring and awareness of one's own memorial activity, and selection and use of mnemonic strategies. Niederehe stated that psychological factors, like personality characteristics, can affect the ability to judge one's own metamemory. This may explain why people with cognitive deficits who are able to compensate for their deficits may report no complaints, whereas other people with cognitive deficits may experience complaints because of a lack of this compensation mechanism. On the contrary, people without cognitive deficits may experience cognitive complaints. According to Stulemeijer et al., this results from the fact that subtle cognitive changes might force patients, with good functional outcome, to use additional cognitive resources in order to perform within normal limits, which may lead to the experience of cognitive failure and, as such, give rise to cognitive complaints (Stulemeijer, Vos, Bleijenberg, \& van der Werf, 2007). As shown in the healthy elderly population, psychological factors such as coping styles and premorbid personality characteristics (e.g., neuroticism, extraversion) seem to make some individuals more prone to experiencing cognitive complaints than others (Hanninen et al., 1994; Slavin et al., 2010), and are therefore of growing interest. In multiple sclerosis and chronic pain patients, associations were found between cognitive complaints and dysfunctional coping styles (Roth, Geisser, Theisen-Goodvich, \& Dixon, 2005; van der Hiele, SpliethoffKamminga, Ruimschotel, Middelkoop, \& Visser, 2012). In epilepsy patients, neuroticism showed a significant relationship to the amount of cognitive complaints (Uijl et al., 2006). Only one study investigated the influence of psychological factors in stroke patients, showing that high neuroticism and low memory self-efficacy were associated with more subjective cognitive complaints (Aben et al., 2011). However, only bivariate analyses were performed, so that the degree to which psychological factors relate to cognitive complaints in addition to other factors such as, for example, cognitive functioning and mood is still unclear.

Knowledge of the factors underlying cognitive complaints in stroke patients may have important consequences for stroke care, ultimately resulting in better personalised rehabilitation programmes. Therefore, the aim of this study was (1) to examine the influence of psychological factors on 
subjective cognitive complaints in a large sample of stroke patients, concentrating on proactive coping, passive coping, self-efficacy, optimism, pessimism, extraversion, and neuroticism, and (2) to examine the influence of these factors, after taking several demographic and stroke-related characteristics, cognitive deficits and emotional problems into account.

\section{METHODS}

\section{Design and procedure}

The current cross-sectional study is part of the prospective longitudinal Restore4Stroke cohort study, in which stroke patients are followed for 2 years (van Mierlo et al., 2014). Patients were recruited from stroke units in six participating hospitals in The Netherlands between March 2011 and March 2013. The present study reports data from stroke onset and 2 months post-stroke. The first assessment (T1) consisted of demographic and stroke-related factors, assessed by a trial nurse at the participating hospitals four days post-stroke. After 2 months (T2) patients were asked to complete the self-report scales of depression, anxiety and psychological factors. Furthermore, assessments of cognitive complaints and cognitive functioning were conducted by a trained research assistant at T2. The Restore4Stroke cohort study was approved by the Medical Ethics Committees of all participating hospitals and informed consent was obtained from all included patients.

\section{Subjects}

Patients were eligible for this study if they had a clinically confirmed diagnosis of stroke (ischaemic or haemorrhagic) and had suffered their stroke in the last 7 days. All patients had to be at least 18 years old. Patients were excluded if they (1) had a serious other condition whereby an interference with the study outcomes was expected (e.g., neuromuscular disease); (2) were already dependent regarding activities of daily living before their stroke as defined by a Barthel Index score of 17 or lower; (3) had insufficient command of the Dutch language to understand and complete the questionnaires; or (4) were already suffering from cognitive decline as defined by a score of 1 or higher on the Heteroanamnesis List Cognition (Meijer, van Limbeek, \& de Haan, 2006) before their stroke.

\section{Measures}

The presence of subjective cognitive complaints was assessed using the cognitive complaints scale of the Checklist for Cognitive and Emotional consequences following stroke (CLCE-24), which consists of 13 items (e.g., problems with "doing two things at once" or "remembering new 
information") (van Heugten, Rasquin, Winkens, Beusmans, \& Verhey, 2007). The interviewer scores a "0" for absence and a " 1 " for presence of complaints; the sum score indicates the number of experienced complaints. The CLCE-24 is a feasible and valid instrument to use in stroke patients (van Heugten et al., 2007; Passier et al., 2010).

Demographic characteristics included sex, age and level of education. We recorded the patients' level of education according to a Dutch classification system ranging from $1=$ did not finish primary school, to $7=$ university education (Verhage, 1964). The hemisphere involved, the type of stroke (ischaemic or haemorrhagic) and history of previous stroke(s) were obtained from medical charts. The severity of the stroke was assessed with the National Institutes of Health Stroke Scale (NIHSS; Brott et al., 1989). Activities of daily living (ADL) were assessed by the Barthel Index (BI; Collin, Wade, Davies, \& Horne, 1988). Comorbidity was scored on the Cumulative Illness Rating Scale (CIRS; Linn, Linn, \& Gurel, 1968), assessing physical impairment based on the function of 13 organ areas. The degree of severity is measured on a 5-point scale, ranging from "none" to "extremely". The total comorbidity score is the sum of all 13 items. Cognitive functioning was assessed with the Montreal Cognitive Assessment (MoCA; Nasreddine et al., 2005), using total scores. The MoCA is a screening tool for mild cognitive impairment. In 2006, the National Institute of Neurological Disorders and Stroke - Canadian Stroke Network recommended the MoCA for the assessment of post-stroke cognitive impairment (Hachinski et al., 2006). The MoCA seems to be a more sensitive test in detecting mild cognitive impairment (post-stroke) than the Mini-Mental State Examination (Pendlebury, Cuthbertson, Welch, Mehta, \& Rothwell, 2010; Pendlebury, Mariz, Bull, Mehta, \& Rothwell, 2012).

To study anxiety and depressive symptoms we administered the Hospital Anxiety and Depression Scale (HADS; Spinhoven et al., 1997). Depression and anxiety scores were evaluated separately, using total scores on each subscale.

Proactive coping was measured using the Proactive Coping Competence Inventory (PCI; Bode, Thoolen, \& de Ridder, 2008). The PCI consists of 21 items scored on a 4-point scale, with scores of competence ranging from "not at all" to "very". An example question is "To what extent do you have the capacity to recognise signals that something might go wrong?". The PCI has shown good psychometric properties (Bode et al., 2008).

Passive coping was measured with the passive reaction pattern subscale of the Utrecht Coping List (UCL-P; Schreurs, van de Willige, Brosschot, Tellegen, \& Graus, 1993). This subscale consists of 7 items, which are scored on a 4-point scale ranging from "seldom" to "very often" (e.g., "taking refuge in fantasies"). The internal consistency of this subscale is moderate and the test-retest reliability is high (Schreurs et al., 1993). 
Self-efficacy was measured with the General Self-Efficacy Scale (GSES; Scholz, Dona, Sud, \& Schwarzer, 2002). This scale consists of 10 items scored on a 4-point scale, ranging from "not at all true" to "exactly true" (e.g., "I am confident that I could deal efficiently with unexpected events"). Psychometric properties of the GSES are satisfactory to good (Scholz et al., 2002).

Optimism and pessimism were assessed with the Life Orientation TestRevised (LOT-R; Scheier, Carver, \& Bridges, 1994). This test consists of 10 items; 3 items measuring optimism (e.g., "In uncertain times, I usually expect the best"), 3 items measuring pessimism (e.g., "If something can go wrong for me, it will") and 4 distractor items. Items are scored on a 5-point scale, ranging from 0: "strongly disagree" to 4: "strongly agree". Internal consistency is sufficient (Cronbach's alpha coefficient .78) (Scheier et al., 1994).

Extraversion and neuroticism were measured with the Eysenck Personality Questionnaire-Revised Short Scale, consisting of 12 items on extraversion (EPQ-RSS-E) and 12 items on neuroticism (EPQ-RSS-N) (Sanderman, Arrindell, \& Ranchor, 1995). The items have dichotomous (yes/no) response options (e.g., "Are you a talkative person?" on the extraversion scale, and "Does your mood often go up and down?" on the neuroticism scale). It has shown good internal consistency, test-retest reliability and concurrent validity (Sato, 2005).

\section{Statistical analyses}

Descriptive statistics were used to describe patients' characteristics. Level of education was dichotomised into low (0-5) and high (6-7) (Passier et al., 2010). Frequencies of the separate items on the CLCE- 24 were calculated to explore the profile of complaints.

Bivariate associations of demographic characteristics (age, sex, education), stroke-related factors (hemisphere, type, recurrence, NIHSS, BI), comorbidity (CIRS), cognitive functioning (MoCA total score), emotional problems (HADS-A and HADS-D total scores), and psychological factors (PCI, UCL-P, GSES, LOT-R, EPQ-RSS) with the CLCE-24 cognition score were tested using Spearman correlations. Correlations between psychological factors and HADS were tested as well. Preliminary analyses were conducted to ensure no violation of the assumptions of normality, linearity, multicollinearity (correlation coefficient $>0.7)$ and homoscedasticity. The factors significantly correlating with subjective cognitive complaints $(p<$ .05 ) were used in a hierarchical multiple regression analysis. First, psychological factors were entered as independent variables to study the amount of variance of cognitive complaints explained by the psychological factors alone (step 1). Subsequently, we adjusted for demographic characteristics (step 2), stroke-related factors and comorbidity (step 3), cognitive functioning (step 4) and emotional problems (step 5), at each step entering psychological 
factors in the last block in the regression models. Analyses were performed with IBM SPSS Statistics version 21.

\section{RESULTS}

\section{Subjects}

A total of 395 patients were included in the Restore4Stroke cohort study. The data of 350 patients $(88.6 \%)$ were available for analysis. Three patients died and 18 refused further participation. Furthermore, 5 patients were excluded from the current study because of their aphasia and in 19 patients it was not possible to conduct the $\mathrm{T} 2$ assessment because of their general physical condition.

The characteristics of the 350 patients are displayed in Table 1 . At the onset of stroke, mean age was 66.6 years $(S D=12.4), 63.7 \%$ of the patients were male, and $93.4 \%$ suffered an ischaemic stroke. The descriptive statistics of the psychological measures are presented in Table 2.

\section{Cognitive complaints}

Two months post-stroke, 270 patients (68.4\%) reported at least one cognitive complaint as assessed by the CLCE-24. The proportions of patients with cognitive complaints are shown in Table 3 . The most reported cognitive complaints were mental slowness, attention problems and memory problems for new information. The mean number of cognitive complaints per patient was $3.17(S D=2.88)$.

\section{Correlations with cognitive complaints}

Table 4 shows bivariate and multivariate relationships with the CLCE- 24 cognition score. Because of the disproportionate distribution of ischaemic and haemorrhagic strokes, type of stroke was eventually not included in the analyses.

Bivariate analyses showed that female sex, younger age, presence of recurrent stroke(s), more comorbidity (CIRS), poor cognitive functioning (MoCA), more depressive symptoms (HADS-D), more anxiety (HADS-A), less proactive coping (PCI), more passive coping (UCL-P), less self-efficacy (GSES), less optimism (LOT-R), more pessimism (LOT-R), less extraversion (EPQRSS-E) and more neuroticism (EPQ-RSS-N) were significantly associated with higher scores on the CLCE-24 cognition domain. No multicollinearity was found between these variables. Bivariate correlations between most psychological factors and total HADS score were moderate (Spearman's rho $=.622$ for UCL-P, .533 for EPQ-RSS-N, - .405 for PCI, - .401 for LOT-R optimism, -.354 for GSES, .332 for LOT-R pessimism, and -.107 for EPQ-SS-E). 
TABLE 1

Characteristics of stroke patients $(n=350)$ at T1

\begin{tabular}{|c|c|c|}
\hline & $\mathrm{n}$ & $\%$ \\
\hline \multicolumn{3}{|l|}{ Demographic characteristics } \\
\hline Sex, number of men & 223 & 63.7 \\
\hline Age in years, mean $(S D)$ & $66.6(12.4)$ & \\
\hline \multicolumn{3}{|l|}{ Education level $(n=349)$} \\
\hline Low $(1-5)$ & 254 & 72.8 \\
\hline High (6-7) & 95 & 27.2 \\
\hline \multicolumn{3}{|l|}{ Stroke characteristics } \\
\hline \multicolumn{3}{|l|}{ Type of stroke $(n=349)$} \\
\hline Ischaemic & 326 & 93.4 \\
\hline Haemorrhagic & 23 & 6.6 \\
\hline \multicolumn{3}{|l|}{ Location of stroke $(n=345)$} \\
\hline Left & 137 & 39.7 \\
\hline Right & 150 & 43.5 \\
\hline Vertebrobasilar & 58 & 16.8 \\
\hline Recurrent stroke & 45 & 12.9 \\
\hline NIHSS score, mean $(S D)$ & $2.5(2.9)$ & \\
\hline No stroke symptoms (NIHSS 0) & 87 & 24.9 \\
\hline Minor stroke symptoms (NIHSS 1-4) & 202 & 57.7 \\
\hline Moderate stroke symptoms (NIHSS 5-12) & 56 & 16.0 \\
\hline Moderate to severe symptoms (NIHSS > 12) & 5 & 1.5 \\
\hline Barthel Index, mean $(S D)$ & $17.1(4.5)$ & \\
\hline ADL independent (BI 19-20) & 208 & 59.4 \\
\hline ADL $(\mathrm{BI}<19)$ & 142 & 40.6 \\
\hline Duration of hospital stay in days, mean $(S D)$ & $8.4(6.3)$ & \\
\hline \multicolumn{3}{|l|}{ Destination after discharge from hospital } \\
\hline Home & 255 & 72.9 \\
\hline Rehabilitation centre & 49 & 14.0 \\
\hline Nursing home & 46 & 13.1 \\
\hline Cognition (MoCA at T2), mean $(S D)(n=349)$ & $23.6(4.0)$ & \\
\hline Normal cognition (MoCA 26-30) & 113 & 32.4 \\
\hline Cognitively impaired (MoCA < 26) & 236 & 67.6 \\
\hline \multicolumn{3}{|l|}{ Emotional characteristics } \\
\hline HADS depression, mean $(S D)(n=343)$ & $4.6(3.9)$ & \\
\hline No depressive symptoms (HADS-D 0-7) & 269 & 78.4 \\
\hline Depressive symptoms (HADS-D > 7) & 74 & 21.6 \\
\hline HADS anxiety, mean $(S D)(n=343)$ & $4.7(3.9)$ & \\
\hline No anxiety (HADS-A 0-7) & 273 & 79.6 \\
\hline Anxiety (HADS-A > 7) & 70 & 20.4 \\
\hline
\end{tabular}

$\mathrm{T} 1=$ first assessment $<4$ days after stroke; NIHSS $=$ National Institutes of Health Stroke Scale; MoCA $=$ Montreal Cognitive Assessment; T2 = assessment 2 months after stroke; HADS $=$ Hospital Anxiety and Depression Scale.

In the multiple regression analysis, psychological factors alone explained $34.7 \%$ of the variance in the CLCE-24 cognition score. After stepwise adjustment for significant demographic characteristics, 
TABLE 2

Descriptive statistics of the psychological measures

\begin{tabular}{llccr}
\hline Psychological factor & Measure & Range & $\mathrm{N}$ & Mean (SD) \\
\hline Proactive coping & PCI & $1-4$ & 346 & $3.1(0.6)$ \\
Passive coping & UCL-P & $7-28$ & 347 & $10.6(2.9)$ \\
Self-efficacy & GSES & $10-40$ & 346 & $31.6(6.4)$ \\
Optimism & LOT-R & $0-12$ & 347 & $8.2(2.1)$ \\
Pessimism & LOT-R & $0-12$ & 346 & $4.4(2.8)$ \\
Extraversion & EPQ-RSS-E & $0-12$ & 346 & $7.1(3.2)$ \\
Neuroticism & EPQ-RSS-N & $0-12$ & 347 & $3.7(3.2)$ \\
\hline
\end{tabular}

$\mathrm{PCI}=$ Proactive Coping Competence Inventory; UCL-P = passive reaction pattern subscale of the Utrecht Coping List; GSES = General Self-Efficacy Scale; LOT-R $=$ Life Orientation TestRevised, EPQ-RSS = Eysenck Personality Questionnaire Revised Short Scale.

TABLE 3

Cognitive complaints in stroke patients $(n=350)$, as assessed with the CLCE-24

\begin{tabular}{lcc}
\hline Cognitive complaints since stroke & $\mathrm{n}$ & $\%$ \\
\hline Keeping up; has become slower & 181 & 51.7 \\
Attending to things & 148 & 42.3 \\
Remembering new information & 138 & 39.4 \\
Doing two things at once & 135 & 38.6 \\
Speaking or writing & 99 & 28.3 \\
Taking initiative & 84 & 24.0 \\
Planning and organising things & 82 & 23.4 \\
Perceiving time & 60 & 17.1 \\
Social aspects of language & 54 & 15.4 \\
Remembering old information & 52 & 14.9 \\
Performing daily activities & 35 & 10.0 \\
Attending to a part of the body or space & 29 & 8.3 \\
Orientating to places or persons & 12 & 3.4 \\
\hline
\end{tabular}

CLCE-24 = Checklist for Cognitive and Emotional consequences following stroke.

stroke-related factors, CIRS and MoCA, the explained variance by psychological factors dropped to 22.6\%. Adjusting for HADS in the final step caused the largest decrease, from $22.6 \%$ to $8.5 \%$. In the final regression model, total explained variance was $52.3 \%$ (Table 4). Age, cognition (MoCA), depressive symptoms (HADS-D) and proactive coping (PCI) were independently associated with cognitive complaints $(p<.001)$. The presence of depressive symptoms was most strongly related (Beta $=$ $0.380)$. 
TABLE 4

Bivariate and multivariate analyses of independent variables and CLCE-24 cognition score two months post-stroke $(n=350)$

\begin{tabular}{|c|c|c|c|c|c|c|c|c|c|}
\hline \multirow[b]{3}{*}{ Factors } & \multirow[b]{3}{*}{ Measure } & \multirow{3}{*}{$\begin{array}{c}\begin{array}{c}\text { Bivariate } \\
\text { analysis }\end{array} \\
\begin{array}{c}\text { Spearman's } \\
\text { rho }\end{array}\end{array}$} & \multicolumn{7}{|c|}{ Multivariate analysis } \\
\hline & & & \multirow[b]{2}{*}{ Beta } & \multirow[b]{2}{*}{$\mathrm{p}$-value } & \multicolumn{5}{|c|}{ Explained variance per step ( $\mathrm{R}$ square change) } \\
\hline & & & & & Step 1 & Step 2 & Step 3 & Step 4 & Step 5 \\
\hline Demographic factors & & & & & - & $4.0 \%$ & $4.0 \%$ & $4.0 \%$ & $4.0 \%$ \\
\hline Sex (female) & & $.127^{*}$ & 0.053 & .19 & & & & & \\
\hline Age & & $-.132^{*}$ & -0.281 & $<.001$ & & & & & \\
\hline Education (high) & & -.085 & - & & & & & & \\
\hline Stroke-related factors & & & & & - & - & $7.2 \%$ & $7.2 \%$ & $7.2 \%$ \\
\hline $\begin{array}{l}\text { Side of stroke (right vs. left }+ \\
\quad \text { vertebrobasilar) }\end{array}$ & & .028 & - & & & & & & \\
\hline Severity of stroke & NIHSS & .070 & - & & & & & & \\
\hline $\mathrm{ADL}$ & BI & -.052 & - & & & & & & \\
\hline Recurrent stroke(s) & & $.130^{*}$ & 0.094 & .017 & & & & & \\
\hline Comorbidity & CIRS & $.201^{* *}$ & 0.059 & .18 & & & & & \\
\hline Cognition & & & & & - & - & - & $11.4 \%$ & $11.4 \%$ \\
\hline Cognitive performance & $\mathrm{MoCA}$ & $-.235^{* *}$ & -0.262 & $<.001$ & & & & & \\
\hline
\end{tabular}


Emotional problems

Anxiety

Proactive coping

Passive coping

Self-efficacy

Optimism

Pessimism

Extraversion

Neuroticism

Total explained variance
Depressive symptoms

Psychological factors

\begin{tabular}{|c|c|c|c|c|c|c|c|c|}
\hline & & & & - & - & - & - & $21.2 \%$ \\
\hline HADS-D & $.542^{* *}$ & 0.380 & $<.001$ & & & & & \\
\hline \multirow[t]{2}{*}{ HADS-A } & $.445^{* *}$ & -0.078 & .21 & & & & & \\
\hline & & & & $34.7 \%$ & $33.2 \%$ & $27.4 \%$ & $22.6 \%$ & $8.5 \%$ \\
\hline PCI & $-.479^{* *}$ & -0.245 & $<.001$ & $F 25.6$ & $F$ change & $F$ change & $F$ change & $F$ change \\
\hline UCL-P & $.453^{* *}$ & 0.027 & .64 & & 25.4 & 21.2 & 19.6 & 8.3 \\
\hline GSES & $-.398^{* *}$ & -0.066 & .20 & $p<.001$ & $p<.001$ & $p<.001$ & $p<.001$ & $p<.001$ \\
\hline LOT-R & $-.370^{* *}$ & 0.005 & .91 & & & & & \\
\hline LOT-R & $.178^{* *}$ & -0.076 & .079 & & & & & \\
\hline EPQ-RSS-E & $-.107^{*}$ & 0.009 & .84 & & & & & \\
\hline \multirow[t]{2}{*}{ EPQ-RSS-N } & $.446^{* *}$ & 0.103 & .066 & & & & & \\
\hline & & & & $34.7 \%$ & $37.2 \%$ & $38.6 \%$ & $45.2 \%$ & $52.3 \%$ \\
\hline
\end{tabular}

CLCE-24 = Checklist for Cognitive and Emotional consequences following stroke; NIHSS = National Institutes of Health Stroke Scale; BI = Barthe Index; CIRS = Cumulative Illness Rating Scale; MoCA = Montreal Cognitive Assessment; HADS = Hospital Anxiety and Depression Scale; PCI = Proactive Coping Competence Inventory; UCL-P = passive reaction pattern subscale of the Utrecht Coping List; GSES = General Self-Efficacy Scale; LOT-R = Life Orientation Test-Revised, EPQ-RSS = Eysenck Personality Questionnaire Revised Short Scale.

$*=p<.05{ }^{* *}=p<.01$. 


\section{DISCUSSION}

Our study showed that $68.4 \%$ of the patients reported at least one cognitive complaint 2 months after stroke. All psychological factors investigated were bivariately related to cognitive complaints, and still explained, in combination with all other variables, a significant proportion of the variance of such complaints. Proactive coping was significantly independently related in the regression analysis, showing that more proactive coping was related to fewer cognitive complaints. Other factors that were significantly independently associated were age, cognition and depressive symptoms, the latter being most strongly related.

The strong relationship between depressive symptoms and cognitive complaints may be explained by the fact that some cognitive complaints, such as attention problems and mental slowness, can be manifestations of depressed mood. The fact that the explained variance by psychological factors dropped from $22.6 \%$ to $8.5 \%$ after adjusting for emotional problems, shows that they share some variance. This may not be surprising, as psychological factors also influence emotional status, in particular mood (Aben et al., 2002). Consequently, the influence of psychological factors on cognitive complaints is larger than our results may presume, due to their indirect effect.

A significant correlation between cognitive performance and cognitive complaints was found in our study, showing that poor cognitive performance was related to more complaints and vice versa. The validation study of the CLCE-24 (van Heugten et al., 2007) showed a significant relationship as well, based on scores on the Mini-Mental State Examination (MMSE) and CAMCOG (cognitive part of the Cambridge Examination for Mental Disorders of the Elderly). Two other studies using the MMSE also observed a negative correlation between cognitive complaints and cognitive performance (Narasimhalu, Wiryasaputra, Sitoh, \& Kandiah, 2013; Xiong et al., 2011). When neuropsychological examination is performed using more comprehensive tests, most studies did not find a significant association (Aben $\mathrm{L}$ et al., 2011; Duits et al., 2008; Winkens, Van Heugten, Fasotti, \& Wade, 2009). Since MoCA assesses overall cognitive functioning, in comparison to detailed tests in extensive neuropsychological assessments to find even the smallest deficits, we may presume that, in daily practice, problems in overall cognitive functioning will be noticed sooner than small cognitive deficits. As a consequence, cognitive complaints may thus relate better to MoCA scores. The $\mathrm{MoCA}$ is a sensitive instrument to detect post-stroke cognitive impairment (Koski, 2013).

Our study showed that younger age is associated with more cognitive complaints. An explanation may be that younger people are expected to perform more challenging tasks in daily life, and experience more demands on their cognitive abilities, compared to older people. Before their stroke, they lived 
active lives and are therefore more highly affected by these post-stroke problems.

\section{Strengths and limitations}

One of the strengths of this study is the large group of stroke patients included. Furthermore, the influence of a combination of psychological factors on cognitive complaints has been investigated for the first time. Finally, in this study, demographic characteristics, stroke-related factors, cognition, emotional problems and psychological factors have been investigated in a multivariate analysis for their influence on cognitive complaints. This resulted in a more complete overview of the factors that determine cognitive complaints 2 months post-stroke.

However, some limitations should also be mentioned. First, patients with an ischaemic stroke were over-represented in our cohort study. Ninetythree percent of the patients suffered an ischaemic stroke, against $82 \%$ in the total stroke population in The Netherlands (Vaartjes et al., 2008). This is probably a result of recruiting patients from general hospitals and not from academic hospitals. Another reason could be that in general, haemorrhagic lesions are more severe, causing patients not to be able to receive information about the study and to agree to participate within one week after the onset of stroke. Second, our results were not compared with a demographically matched control group. Third, the coping style measures used were not specifically designed with respect to coping with subjective cognitive complaints. A stronger relationship between coping and subjective cognitive complaints may have been found if we had used a measure of coping specifically developed with respect to cognitive complaints. However, to our knowledge such a coping style measure does not exist. The development of such a measure might assist further research in this area. Finally, our study had a cross-sectional design, therefore was not able to determine causality between psychological factors and cognitive complaints.

\section{Clinical implications}

As stroke patients make less use of proactive coping styles compared to other brain damaged patients (Herrmann et al., 2000), any intervention to support proactive coping is needed. Several interventions, such as problem solving therapy, are aimed at changing maladaptive coping styles. These interventions proved to be effective in patients with traumatic brain injury (Backhaus, Ibarra, Klyce, Trexler, \& Malec, 2010), chronic pain (Merlijn et al., 2005) and breast cancer (Hopko et al., 2011), and is currently being investigated in stroke patients (Tielemans et al., 2014). Recognising coping styles and intervening on dysfunctional coping styles may eventually result in better personalised stroke care, hopefully leading to a decrease in cognitive complaints. 
Comparable to coping, post-stroke depressed mood can be influenced by therapeutic interventions such as problem solving therapy (Hackett, Anderson, House, \& Halteh, 2008). There is some proof that cognitive complaints diminish when mood is improved (Antikainen et al., 2001). Therefore, mood is an important target for intervention in stroke care.

\section{CONCLUSION}

Cognitive complaints are common two months after stroke and are associated with psychological factors. Since some psychological factors can be improved by therapeutic interventions, it is important to focus on these factors in stroke care.

\section{REFERENCES}

Aben, I., Denollet, J., Lousberg, R., Verhey, F., Wojciechowski, F., \& Honig, A. (2002). Personality and vulnerability to depression in stroke patients: A 1-year prospective follow-up study. Stroke, 33, 2391-2235.

Aben, L., Ponds, R. W., Heijenbrok-Kal, M. H., Visser, M. M., Busschbach, J. J., \& Ribbers, G. M. (2011). Memory complaints in chronic stroke patients are predicted by memory self-efficacy rather than memory capacity. Cerebrovascular Diseases, 31, 566-572.

Antikainen, R., Hanninen, T., Honkalampi, K., Hintikka, J., Koivumaa-Honkanen, H., Tanskanen, A., \& Viinamaki, H. (2001). Mood improvement reduces memory complaints in depressed patients. European Archives of Psychiatry and Clinical Neuroscience, 251, 6-11.

Backhaus, S. L., Ibarra, S. L., Klyce, D., Trexler, L. E., \& Malec, J. F. (2010). Brain injury coping skills group: A preventative intervention for patients with brain injury and their caregivers. Archives of Physical Medicine and Rehabilitation, 91, 840-848.

Barker-Collo, S., Feigin, V. L., Parag, V., Lawes, C. M., \& Senior, H. (2010). Auckland stroke outcomes study: Part 2: Cognition and functional outcomes 5 years poststroke. Neurology, $75,1608-1616$.

Bode, C., Thoolen, B., \& de Ridder, D. (2008). Het meten van proactieve copingvaardigheden: psychometrische eigenschappen van de Utrechtse Proactieve Coping Competentie lijst (UPCC). Psychologie \& Gezondheid, 36, 81-91.

Brott, T., Adams, H. P. Jr., Olinger, C. P., Marler, J. R., Barsan, W. G., Biller, J., . . Hertzberg, V. (1989). Measurements of acute cerebral infarction: A clinical examination scale. Stroke, 20, 864-870.

Collin, C., Wade, D. T., Davies, S., \& Horne, V. (1988). The Barthel ADL index: A reliability study. Disability \& Rehabilitation, 10, 61-63.

Duits, A., Munnecom, T., van Heugten, C., \& van Oostenbrugge, R. J. (2008). Cognitive complaints in the early phase after stroke are not indicative of cognitive impairment. Journal of Neurology, Neurosurgery \& Psychiatry, 79, 143-146.

Hachinski, V., Iadecola, C., Petersen, R. C., Breteler, M. M., Nyenhuis, D. L., Black, S. E., .. Leblanc, G. G. (2006). National institute of neurological disorders and stroke-Canadian stroke network vascular cognitive impairment harmonization standards. Stroke, 37, $2220-2241$. 
Hackett, M. L., Anderson, C. S., House, A., \& Halteh, C. (2008). Interventions for preventing depression after stroke. Cochrane Database of Systematic Reviews, (3), CD003689. doi:10.1002/14651858.CD003689.pub3

Hanninen, T., Reinikainen, K. J., Helkala, E. L., Koivisto, K., Mykkanen, L., Laakso, M., ... Riekkinen, P. J. (1994). Subjective memory complaints and personality traits in normal elderly subjects. Journal of the American Geriatrics Society, 42, 1-4.

Herrmann, M., Curio, N., Petz, T., Synowitz, H., Wagner, S., Bartels, C., \& Wallesch, C. W. (2000). Coping with illness after brain diseases-A comparison between patients with malignant brain tumors, stroke, Parkinson's disease and traumatic brain injury. Disability \& Rehabilitation, 22, 539-546.

van Heugten, C., Rasquin, S., Winkens, I., Beusmans, G., \& Verhey, F. (2007). Checklist for cognitive and emotional consequences following stroke (CLCE-24): Development, usability and quality of the self-report version. Clinical Neurology and Neurosurgery, 109, 257-262.

van der Hiele, K., Spliethoff-Kamminga, N. G., Ruimschotel, R. P., Middelkoop, H. A., \& Visser, L. H. (2012). The relationship between self-reported executive performance and psychological characteristics in multiple sclerosis. European Journal of Neurology, 19, $562-569$.

Hopko, D. R., Armento, M. E., Robertson, S. M., Ryba, M. M., Carvalho, J. P., Colman, L. K., . . Lejuez, C. W. (2011). Brief behavioral activation and problem-solving therapy for depressed breast cancer patients: Randomized trial. Journal of Consulting and Clinical Psychology, 79, $834-849$.

Koski, L. (2013). Validity and applications of the Montreal cognitive assessment for the assessment of vascular cognitive impairment. Cerebrovascular Diseases, 36, 6-18.

Lamb, F., Anderson, J., Saling, M., \& Dewey, H. (2013). Predictors of subjective cognitive complaint in postacute older adult stroke patients. Archives of Physical Medicine and Rehabilitation, 94, 1747-1752.

Linn, B. S., Linn, M. W., \& Gurel, L. (1968). Cumulative illness rating scale. Journal of the American Geriatrics Society, 16, 622-626.

Meijer, R., van Limbeek, J., \& de Haan, R. (2006). Development of the stroke-unit discharge guideline: choice of assessment instruments for prediction in the subacute phase poststroke. International Journal of Rehabilitation Research, 29, 1-8.

Merlijn, V. P., Hunfeld, J. A., van der Wouden, J. C., Hazebroek-Kampschreur, A. A., van Suijlekom-Smit, L. W., Koes, B. W., \& Passchier, J. A. (2005). Cognitive-behavioural program for adolescents with chronic pain-a pilot study. Patient Education and Counseling, 59, $126-134$.

van Mierlo, M. L., Van Heugten, C. M., Post, M. W., Lindeman, E., de Kort, P. L., \& VisserMeily, J. M. (2014). A longitudinal cohort study on quality of life in stroke patients and their partners: Restore4Stroke cohort. International Journal of Stroke, 9(1), 148-154.

Narasimhalu, K., Wiryasaputra, L., Sitoh, Y. Y., \& Kandiah, N. (2013). Post-stroke subjective cognitive impairment is associated with acute lacunar infarcts in the basal ganglia. European Journal of Neurology, 20, 547-551.

Nasreddine, Z. S., Phillips, N. A., Bedirian, V., Charbonneau, S., Whitehead, V., Collin, I., ... Chertkow, H. (2005). The montreal cognitive assessment, MoCA: A brief screening tool for mild cognitive impairment. Journal of the American Geriatrics Society, 53, 695-699.

Niederehe, G. (1998). The significance of memory complaints in later life: Methodological and theoretical considerations. In J. Lomranz (Eds.), Handbook of aging and mental health: An integrative approach (pp. 417-434). New York: Plenum Press.

Passier, P. E., Visser-Meily, J. M., van Zandvoort, M. J., Post, M. W., Rinkel, G. J., \& van Heugten, C. (2010). Prevalence and determinants of cognitive complaints after aneurysmal subarachnoid hemorrhage. Cerebrovascular Diseases, 29, 557-563. 
Passier, P. E., Visser-Meily, J. M., van Zandvoort, M. J., Rinkel, G. J., Lindeman, E., \& Post, M. W. (2012). Predictors of long-term health-related quality of life in patients with aneurysmal subarachnoid hemorrhage. NeuroRehabilitation, 30, 137-145.

Pendlebury, S. T., Cuthbertson, F. C., Welch, S. J., Mehta, Z., \& Rothwell, P. M. (2010). Underestimation of cognitive impairment by mini-mental state examination versus the montreal cognitive assessment in patients with transient ischemic attack and stroke: A populationbased study. Stroke, 41, 1290-1293.

Pendlebury, S. T., Mariz, J., Bull, L., Mehta, Z., \& Rothwell, P. M. (2012). MoCA, ACE-R, and MMSE versus the national institute of neurological disorders and stroke-Canadian stroke network vascular cognitive impairment harmonization standards neuropsychological battery after TIA and stroke. Stroke, 43, 464-469.

Pollock, A., St Geroge, B., Fenton, M., \& Firkins, L. (2014). Top 10 research priorities relating to life after stroke - Consensus from stroke survivors, caregivers, and health professionals. International Journal of Stroke, 9(3), 313-320.

van Rijsbergen, M. W., Mark, R. E., de Kort, P. L., \& Sitskoorn, M. M. (2014). Subjective cognitive complaints after stroke: A systematic review. Journal of Stroke and Cerebrovascular Diseases, 23(3), 408-420.

Roth, R. S., Geisser, M. E., Theisen-Goodvich, M., \& Dixon, P. J. (2005). Cognitive complaints are associated with depression, fatigue, female sex, and pain catastrophizing in patients with chronic pain. Archives of Physical Medicine and Rehabilitation, 86, 1147-1154.

Sanderman, R., Arrindell, W. A., \& Ranchor, A. V. (1995). Het meten van persoonlijkheidskenmerken met de Eysenck personality questionnaire (EPQ): Een handleiding. Groningen: Noordelijk Centrum voor Gezondheidsvraagstukken.

Sato, T. (2005). The eysenck personality questionnaire brief version: Factor structure and reliability. The Journal of Psychology, 139, 545-552.

Scheier, M. F., Carver, C. S., \& Bridges, M. W. (1994). Distinguishing optimism from neuroticism (and trait anxiety, self-mastery, and self-esteem): A reevaluation of the Life Orientation Test. Journal of Personality and Social Psychology, 67, 1063-1078.

Scholz, U., Dona, B. G., Sud, S., \& Schwarzer, R. (2002). Is general self-efficacy a universal construct? Psychometric findings from 25 countries. European Journal of Psychological Assessment, 18, 242-251.

Schreurs, P. J. G., van de Willige, G., Brosschot, J. F., Tellegen, B., Graus, G. M. H. (1993). De Utrechtse Coping Lijst: UCL. Omgaan met problemen en gebeurtenissen (herziene handleiding). Lisse: Swets en Zeitlinger.

Slavin, M. J., Brodaty, H., Kochan, N. A., Crawford, J. D., Trollor, J. N., Draper, B., \& Sachdev, P. S. (2010). Prevalence and predictors of "subjective cognitive complaints" in the Sydney memory and ageing study. The American Journal of Geriatric Psychiatry, 18, 701-710.

Spinhoven, P., Ormel, J., Sloekers, P. P., Kempen, G. I., Speckens, A. E., \& Van Hemert, A. M. (1997). A validation study of the hospital anxiety and depression scale (HADS) in different groups of Dutch subjects. Psychological Medicine, 27, 363-370.

Stulemeijer, M., Vos, P. E., Bleijenberg, G., \& van der Werf, S. P. (2007). Cognitive complaints after mild traumatic brain injury: Things are not always what they seem. Journal of Psychosomatic Research, 63(6), 637-645.

Tielemans, N. S., Visser-Meily, J. M., Schepers, V. P., Post, M. W., Wade, D. T., \& Van Heugten, C. M. (2014). Study protocol of the Restore4Stroke self-management study: A multicenter randomized controlled trial in stroke patients and their partners. International Journal of Stroke, 9(6), 818-823.

Uijl, S. G., Uiterwaal, C. S., Aldenkamp, A. P., Carpay, J. A., Doelman, J. C., Keizer, K., . . van Donselaar, C. A. (2006). A cross-sectional study of subjective complaints in patients with epilepsy who seem to be well-controlled with anti-epileptic drugs. Seizure, 15, 242-248. 
Vaartjes, I., Reitsma, J. B., de Bruin, A., Berger-van, S. M., Bos, M. J., Breteler, M. M., . . Bots, M. L. (2008). Nationwide incidence of first stroke and TIA in the Netherlands. European Journal of Neurology, 15, 1315-1323.

Verhage, F. (1964). Intelligentie en leeftijd: onderzoek bij Nederlanders van twaalf tot zevenenzeventig jaar. Assen: Van Gorcum.

Visser-Meily, J. M., Rhebergen, M. L., Rinkel, G. J., van Zandvoort, M. J., \& Post, M. W. (2009). Long-term health-related quality of life after aneurysmal subarachnoid hemorrhage: Relationship with psychological symptoms and personality characteristics. Stroke, 40, $1526-1529$.

Winkens, I., Van Heugten, C. M., Fasotti, L., \& Wade, D. T. (2009). Reliability and validity of two new instruments for measuring aspects of mental slowness in the daily lives of stroke patients. Neuropsychological Rehabilitation, 19, 64-85.

Xiong, Y. Y., Wong, A., Mok, V. C., Tang, W. K., Lam, W. W., Kwok, T. C., ... Wong, L. K. (2011). Frequency and predictors of proxy-confirmed post-stroke cognitive complaints in lacunar stroke patients without major depression. International Journal of Geriatric Psychiatry, 26, 1144-1151. 